\title{
Effects of Polyene Antibiotics on Growth and Sterol-induction of Oospore Formation by Pythium periplocum
}

\author{
BY J. W. HENDRIX AND DOROTHY K. LAUDER \\ Crops Research Division, Agricultural Research Service, U.S. Department \\ of Agriculture, Department of Plant Pathology, University of Kentucky, \\ Lexington, Kentucky 40506, U.S.A.
}

(Received 7 December 1965)

\begin{abstract}
SUMMARY
The effect of polyene antibiotics upon growth and sterol-induction of oospore production by Pythium periplocum was studied. Filipin and fungichromin markedly inhibited growth and prevented reproduction. Amphotericin $\mathbf{B}$ also prevented oospore production but only slightly inhibited growth. Pimaricin slightly inhibited growth and greatly decreased reproduction. Nystatin usually had no effect on growth and slightly stimulated reproduction. At $4 \mu \mathrm{g}$. $/ \mathrm{ml}$., amphotericin $\mathbf{B}$ and fungichromin prevented oospore induction by $1 \mu \mathrm{g}$. cholesterol $/ \mathrm{ml}$. but had no effect on growth. Growth inhibition by amphotericin B and fungichromin was almost completely annulled by higher cholesterol concentrations, and prevention of oospore formation was partially annulled. These results generally support the hypothesis that polyene antibiotics act by interfering with the action of cellular sterols, but the growth inhibition which occurred on sterol-free medium suggests that a second mechanism may be operative.
\end{abstract}

\section{INTRODUCTION}

Pythium and phytophthora species, which comprise a destructive family of plant pathogenic fungi, require an exogenous source of sterol for reproduction by sporangia or oospores (Chee \& Turner, 1965; Elliott, Hendrie, Knights \& Parker, 1964; Hendrix, 1965; Klemmer \& Lenney, 1965). Growth of some (Chee \& Turner, 1965; Hendrix, 1964, 1965), but not all (Hendrix, 1965), species was stimulated by sterols such as cholesterol; also growth of some species may be stimulated by cholesterol but not by other sterols (Hendrix, 1964). In a liquid medium growth stimulation of Phytophthora parasitica var. nicotianae was dependent upon good aeration (Hendrix, Norman \& Apple, 1966). Species of Pythiaceae appear to be unable to synthesize the 3 - $\beta$-hydroxy sterols predominant in plants, animals, or fungi. Sterols such as cholesterol, ergosterol, stigmasterol and the sitosterols are readily precipitated by digitonin; yet digitonin-precipitable compounds were not found in extracts of pythiaceous fungi grown on a sterol-free medium (Elliott et al. 1964; Hendrix, 1966). Pythium aphanidermatum and Phytophthora palmivora, unlike related fungi, were unable to incorporate acetate into digitonin-precipitable compounds (Hendrix, 1966).

Polyene antibiotics, which inhibit a wide spectrum of fungi, had little effect on pythium and phytophthora species and were used in selective media for isolating these fungi (see Eckert \& Tsao, 1962; Vaartaja \& Bumbeeris, 1964). Gottlieb et al. 
(1961) first proposed that the mechanism of action of polyene antibiotics involves an interference by the antibiotic with an essential cellular function of sterols. Since then considerable evidence (reviewed in detail by Demel, van Deenen \& Kinsky, 1965) has indicated that polyene antibiotics alter permeability by interacting with membrane sterols. The present experiments were designed to test the hypothesis that polyene antibiotics would not affect growth of a pythium species but would prevent oospore formation.

\section{METHODS}

Organism. The test fungus Pythium periplocum Drechs. was chosen because its rapid but sparse linear growth on the medium used facilitated direct microscopic observation. Under the conditions of these experiments, it produced oospores in response to cholesterol (Hendrix, 1965) or other sterols (Hendrix, 1964); but on sterol-free media the growth was completely vegetative.

Chemicals. Polyene antibiotics used and their sources were: fungichromin (Merck Sharp \& Dohme Research Laboratories, Rahway, N.J.); filipin (potency $1000 \mu \mathrm{g} . /$ mg.; The Upjohn Company, Kalamazoo, Mich.); nystatin (Mycostatin Process C), potency 4400 units $/ \mathrm{mg}$., and amphotericin B Type 1, potency $842 \mu \mathrm{g} . / \mathrm{mg}$. (The Squibb Institute for Medical Research, New Brunswick, N.J.); pimaricin (Myprozine), potency $975 \mu \mathrm{g} . / \mathrm{mg}$. (American Cyanamid Company, Princeton, N.J.). Cholesterol (U.S.P.) was obtained from Nutritional Biochemicals Corporation, Cleveland, Ohio. The cholesterol preparation used had the same effects on growth and reproduction as a highly purified sample (Hendrix, 1964).

Medium and cultivation. The medium contained 5.4 g. glucose, $1.5 \mathrm{~g} . \mathrm{NaNO}_{3}$, 1.0 g. $\mathrm{KH}_{2} \mathrm{PO}_{4}, 0.5 \mathrm{~g} . \mathrm{MgSO}_{4} \cdot 7 \mathrm{H}_{2} \mathrm{O}, 2 \mathrm{mg}$. thiamine $\mathrm{HCl}, 17 \mathrm{~g}$. agar $/$. deionized water. The medium was adjusted to $\mathrm{pH} 6.0$ before the medium was autoclaved for $10 \mathrm{~min}$. at $121^{\circ}$. The medium was cooled to $55^{\circ}$, and the antibiotics and cholesterol were added with rapid agitation as dimethyl sulphoxide and anhydrous ethanol solutions, respectively. The media were then pipetted into $9 \mathrm{~cm}$. Petri plates (25 ml./plate), and the plates seeded after the agar had solidified.

Inoculum was prepared by transferring the fungus growing on water agar to a small piece of thebasal medium agar placed on another water agar plate. The inoculum ( $3 \mathrm{~mm}$. discs) was taken from the border of the resulting colony after about one week. The fungal material used had been transferred 5-10 times on sterol-free medium.

The plates were incubated at $22^{\circ}$ in paper bags in closed cabinets because of the light sensitivity of polyene antibiotics. They were exposed to light no more than $10 \mathrm{~min}$. daily for growth measurements or oospore counts.

Oospore counts. All oospores in a single $\times 100$ microscope field $\left(2.63 \mathrm{~mm} .{ }^{2}\right)$ of each of the five to seven replicates of each treatment were counted. Counts were made about $1 \mathrm{~cm}$. from the inoculation point. When considerable growth inhibition had occurred, this distance was decreased proportionally. All oospores from the bottom of the plate to the upper surface of the agar were counted. Eventually the mycelia underwent autolysis and the medium became cloudy. Oospore numbers then seemed to decrease, but we believe the apparent decrease was due to the opacity of the medium, not to an actual decrease. Thus the maximum number of 
oospores recorded are given here. The time required for maximal oospore production ranged from 5 to 12 days and averaged 8 days.

Solvent effects. Final solvent concentrations for all treatments, whether or not antibiotics or cholesterol was present, were $1 \mu \mathrm{l}$. ethanol $/ \mathrm{ml}$. and $5 \mu \mathrm{l}$. dimethyl sulphoxide $/ \mathrm{ml}$. Solvent controls were included. Growth was not affected or was stimulated $5-10 \%$ by $1 \mu \mathrm{l}$. ethanol $/ \mathrm{ml}$. sterol-free medium. Dimethyl sulphoxide was usually $5-10 \%$ inhibitory whether or not cholesterol or ethanol was present. Neither solvent appeared to affect reproduction.

Statistics. Variances of various treatments for growth data were found to be equal; therefore an analysis of variance and least significant difference (L.S.D.) for each experiment was computed. Because variances of various treatments for oospore data were unequal, standard errors for each treatment are given.

\section{RESULTS}

\section{Effect of polyene antibiotics on growth and reproduction}

With the exception of nystatin, all five antibiotics inhibited growth (Table 1). When this experiment was repeated, nystatin was not always inhibitory; the other antibiotics were. Filipin and fungichromin were markedly inhibitory. The toxicity of fungichromin, but not filipin, was partially annulled by cholesterol. Oospore formation was completely blocked by amphotericin $\mathrm{B}$, filipin and fungichromin (Table 1). Oospore production was greatly decreased and was erratic in the presence of pimaricin (Fig. 1). Nystatin initially retarded but eventually slightly stimulated oospore formation (Fig. 1, Table 1).

Table 1. Effect of polyene antibiotics on growth and oospore production by Pythium periplocum on a medium without and with cholesterol

Growth measurements were at $71 \mathrm{hr}$ after inoculation. Concentrations of antibiotics and cholesterol were $15 \mu \mathrm{g} . / \mathrm{ml}$. and $1 \mu \mathrm{g} . / \mathrm{ml}$. respectively.

\begin{tabular}{|c|c|c|c|c|}
\hline \multirow[b]{2}{*}{ Antibiotic } & \multicolumn{2}{|c|}{ No cholesterol } & \multicolumn{2}{|c|}{ Cholesterol } \\
\hline & Growth (mm.) & Oospores/field & Growth (mm.) & Oospores/field \\
\hline Amphotericin B & 45 & $\mathbf{0}$ & 60 & $\mathbf{0}$ \\
\hline Filipin & 23 & $\mathbf{0}$ & 17 & o \\
\hline Fungichromin & 7 & $\mathbf{0}$ & 23 & $\mathbf{0}$ \\
\hline Nystatin & 57 & $\mathbf{0}$ & 58 & 74 \\
\hline Pimaricin & 49 & 0 & 57 & 22 \\
\hline None & 61 & $\mathbf{0}$ & 67 & 67 \\
\hline L.S.D. 0.05 & 4 & - & 4 & - \\
\hline L.S.D. 0.01 & $\mathbf{5}$ & . & $\mathbf{5}$ & . \\
\hline
\end{tabular}

Effect of antibiotic concentration on growth and reproduction

Amphotericin B and fungichromin were chosen for further study because amphotericin B blocked reproduction but had relatively little effect on growth and fungichromin blocked reproduction and greatly inhibited growth. Concentrations of $1 \mu \mathrm{g} . / \mathrm{ml}$. or less of both antibiotics had no effect either on growth or reproduction (Table 2). Both antibiotics at $4 \mu \mathrm{g} . / \mathrm{ml}$. had no effect on growth but completely blocked oospore production on medium containing $1 \mu \mathrm{g}$. cholesterol $/ \mathrm{ml}$. At $16 \mu \mathrm{g}$. ml., both antibiotics inhibited growth. 
Table 2. Effect of antibiotic concentration on growth and oospore production by Pythium periplocum on a medium without and with cholesterol

Growth measurements were made at $72 \mathrm{hr}$ after inoculation. Oospore numbers with standard errors are maximal values which occurred 7 or 8 days after inoculation. Cholesterol concentration was $1 \mu \mathrm{g} . / \mathrm{ml}$.

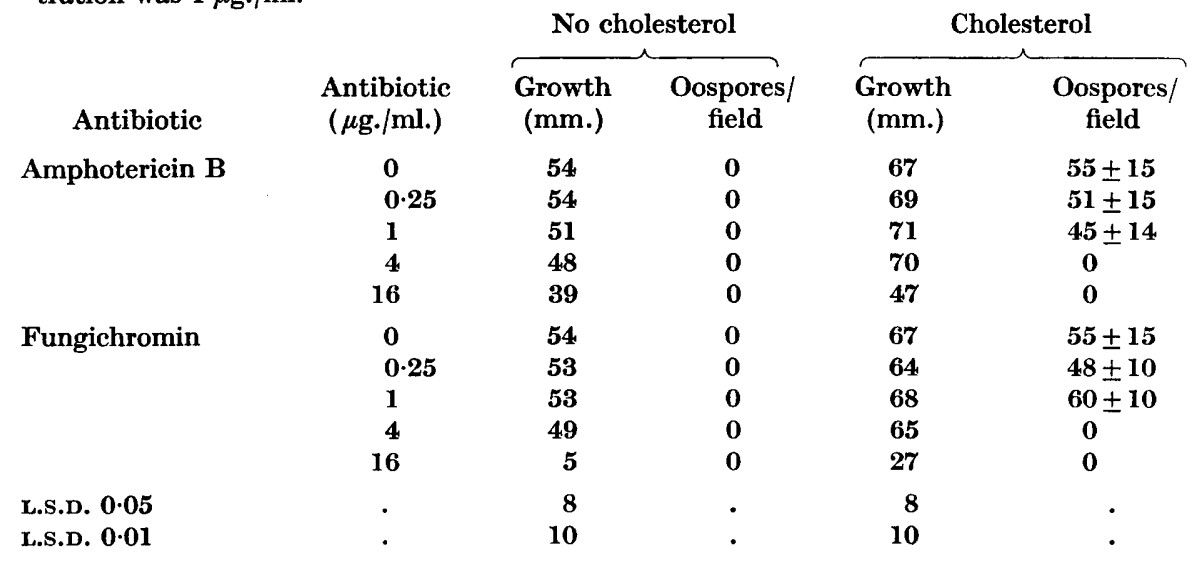

\section{Effect of cholesterol concentration on antibiotic influences}

The toxicity of fungichromin and amphotericin B to growth was considerably decreased as the cholesterol concentration was increased to $10 \mu \mathrm{g} . / \mathrm{ml}$. (Fig. 2). The block to oospore production produced by fungichromin but not amphotericin $\mathbf{B}$ was partially annulled by cholesterol at $10 \mu \mathrm{g} . / \mathrm{ml}$. (Table 3). In other experiments in which the ethanol concentration was raised to permit higher concentrations of

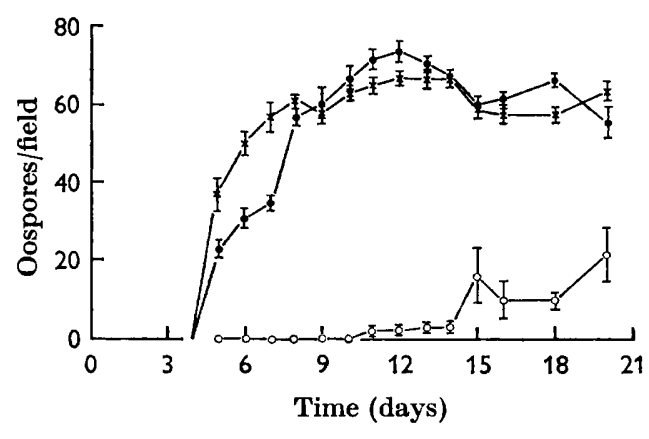

Fig. 1

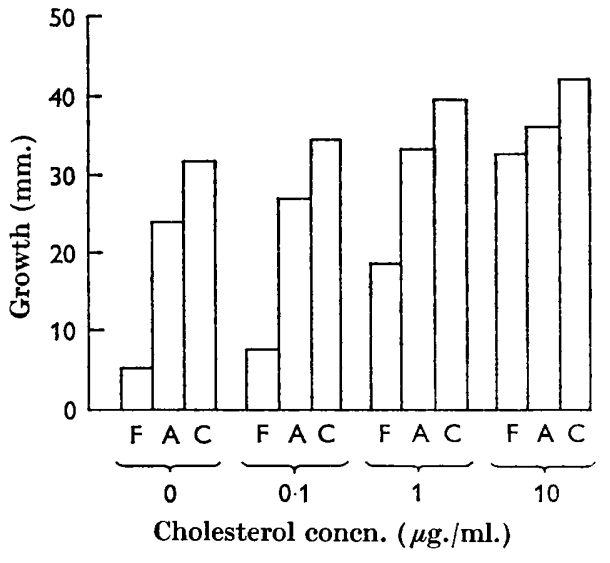

Fig. 2

Fig. 1. Oospore development by Pythium periplocum on a cholesterol-containing medium supplemented by polyene antibiotics. Pimaricin $(O)$, nystatin $(O)$, no antibiotic $(x)$. Brackets enclose \pm standard errors.

Fig. 2. Effect of cholesterol concentration on growth of Pythium periplocum on a medium with and without polyene antibiotics. Fungichromin (F), amphotericin B (A), control (C). Growth measurements were at $47 \mathrm{hr}$ after inoculation. Antibiotic concentrations were $15 \mu \mathrm{g} . / \mathrm{ml}$. L.S.D. 0.05, 2.0 mm. L.S.D. 0.01, 2.7 mm. 
cholesterol, limited oospore formation occurred on media containing $15 \mu \mathrm{g}$. amphotericin $\mathrm{B} / \mathrm{ml}$. and $50 \mu \mathrm{g}$. cholesterol $/ \mathrm{ml}$. However, these experiments are difficult to interpret because the higher ethanol concentrations $(5 \mu \mathrm{l} . / \mathrm{ml}$.) decreased growth and blocked reproduction at low concentrations of cholesterol.

Table 3. Effect of cholesterol concentration on oospore production by Pythium periplocum on a medium without and with antibiotics

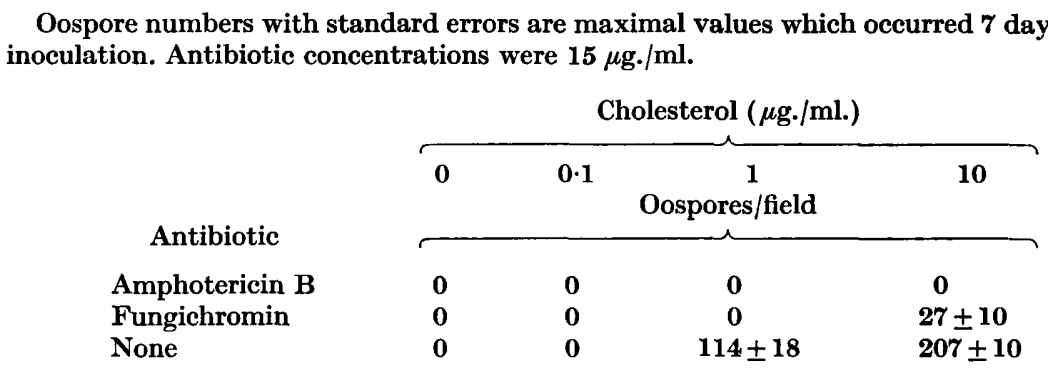

\section{DISCUSSION}

The results generally support the sterol hypothesis about the mode of action of polyene antibiotics since three of the five antibiotics completely blocked oospore formation, a fourth significantly decreased oospore formation and the fifth retarded the initial rate of oospore formation. The eventual stimulation of oospore formation by nystatin is consistent with the experience of Vaartaja \& Bumbeeris (1964), who found that high nystatin concentrations $(500 \mu \mathrm{g} . / \mathrm{ml}$.) stimulated oospore formation by some pythium species. These data agree with the generalization that filipin is the most potent, and nystatin the least potent, of the common polyene antibiotics, amphotericin B and pimaricin occupying intermediate positions (Demel et al. 1965).

The growth responses of Pythium periplocum to polyene antibiotics support the sterol hypothesis in some cases but suggest some other mechanism in others. The extreme growth inhibition on sterol-free medium by filipin and fungichromin suggests another mechanism. Growth inhibition by amphotericin B and fungichromin was annulled by higher concentrations of cholesterol, but the cholesterol may have been preventing toxicity by forming a sterol + antibiotic complex, as suggested by Lampen, Arnow \& Safferman (1960). Fungichromin was considerably more inhibitory to growth than amphotericin B, but inhibition of oospore formation by fungichromin was more easily annulled by cholesterol than by amphotericin $\mathbf{B}$. At $4 \mu \mathrm{g} . / \mathrm{ml}$., neither amphotericin B nor fungichromin affected growth, but both at this concentration blocked oospore production. However, this may merely reflect different sensitivities of growth and reproduction to stimulatory or toxic compounds, for growth stimulation was observed at cholesterol concentrations too small to induce oospore formation.

In most cases the polyene antibiotics did not mask the stimulatory effect of cholesterol on growth. With filipin, however, the fungus grew better on sterol-free medium than on medium containing cholesterol, suggesting an analogy with lysis of Mycoplasma laidlawii by filipin only when the mycoplasma was cultured in the presence of cholesterol (Weber \& Kinsky, 1965). However, amphotericin B 
had an effect similar to that of filipin upon M. laidlawii (Feingold, 1965), while in the present work cholesterol appeared to annul to some extent the toxic effect of amphotericin $\mathbf{B}$.

\section{REFERENCES}

Chee, K. H. \& Turner, N. A. (1965). A steroid factor in pea (Pisum sativum L.) influencing growth and sporulation of Phytophthora cinnamonii Rands. N.Z. J. agric. Res. 8, 104.

Demel, R. A., Van Deenen, L. L. M. \& Kinsky, S. C. (1965). Penetration of lipid monolayers by polyene antibiotics. Correlation with selective toxicity and mode of action. J. biol. Chem. 240, 2749.

Eckert, J. W. \& Tsao, P. H. (1962). A selective antibiotic medium for isolation of Phytophthora and Pythium from plant roots. Phytopathology, 52, 771.

Elliott, C. G., Hendrie, M. R., Knights, B. A. \& Parker, W. (1964). A steroid growth factor requirement in a fungus. Nature, Lond. 203, 427.

Feingold, D. S. (1965). The action of amphotericin B on Mycoplasma laidlawii. Biochem. biophys. Res. Commun. 19, 261.

Gottlieb, D., Carter, H. E., Sloneker, J. H., Wu, L. C. \& Gaudy, E. (1961). Mechanisms of inhibition of fungi by filipin. Phytopathology, 51, 321.

HENDRIX, J. W. (1964). Sterol induction of reproduction and stimulation of growth of Pythium and Phytophthora. Science, 144, 1028.

HENDRIX, J. W. (1965). Influence of sterols on growth and reproduction of Pythium and Phytophthora spp. Phytopathology, 55, 790.

Hendrix, J. W. (1966). Inability of Pythium aphanidermatum and Phytophthora palmivora to incorporate acetate into digitonin-precipitable sterols. Mycologia, 58, in press.

Hendrix, J. W., Norman, C. \& Apple, J. L. (1966). Chemical and physical factors influencing growth of Phytophthora parasitica var. nicotianae on vegetable oils. Physiologia Pl. 19, 159.

Klemer, H. W. \& Lenney, J. F. (1965). Lipids stimulating sexual reproduction and growth in pythiaceous fungi. Phytopathology, 55, 320.

Lampen, J. O., Arnow, P. M. \& Safferman, R. S. (1960). Mechanism of protection by sterols against polyene antibiotics. J. Bact. 80, 200.

VaARTaja, O. \& Bumbeeris, M. (1964). Abundance of Pythium species in nursery soils in South Australia. Aust. J. biol. Sci. 17, 436.

WEBER, M. M. \& KInsky, S. C. (1965). Effect of cholesterol on the sensitivity of Mycoplasma laidlarwii to the polyene antibiotic filipin. J. Bact. 89, 306. 